\title{
An Investigation on the Effective Use of Fly Ash -Fine Grinding of Limestone with Fly Ash as a Grinding Aid-
}

\author{
Naoya KOTAKE*, Kenichi OKAZAKI*, Takanori UJIHARA* and Yoshiteru KANDA* \\ *Department of Chemistry and Chemical Engineering, Yamagata University, 4-3-16, Jonan, Yonezawa, \\ Yamagata, 992-8510 Japan \\ E-mail :nkotake@yz.yamagata-u.ac.jp
}

\begin{abstract}
In this study, the role of fly ash as a grinding aid to facilitate fine grinding of limestone for improved flowability was examined by carrying out batch grinding test for varying feed amount and grinding time, while maintaining the limestone to fly ash ratio at $5: 1$. As a result, it was found that fly ash was an effective grinding aid for the fine grinding of limestone, and the optimum feed amount of limestone and fly ash to the grinding mill increased with increase of grinding time.
\end{abstract}

Key Words : Fly ash, Limestone, Grinding aid, Fine grinding, Ball mill

\section{INTRODUCTION}

In Japan, about 900 million tons of coal ash was generated in 2001 [1] at coal-fired electric power plants and other industries. This amount is increasing each year. However, coal ash utilization has remained constant at $70 \sim 80 \%$ over the last few years. The ratio of fly ash to clinker ash (bottom ash) is about $9: 1$; fly ash is widely used as raw material for cement, in cement mixtures, as road-bed material, etc. The use of fly ash as cement raw material offers environmental advantages by reducing the amount of waste on our land, and also improves the performance and quality of concrete. With the addition of fly ash to Portland cement, the strength of the concrete increases while its permeability decreases, and the alkali-aggregate reaction within it is reduced.

Limestone, the main component of Portland cement, is a self-sufficient mineral resource in Japan. The amount produced in Japan is about $150 \sim 160$ million tons per year.

In this study, we conducted a comminution of limestone with fly ash as a grinding aid [2-4]. Our purpose was to examine the fine grindability of a limestone-fly ash mixture, and that of the limestone in the mixture to produce better fly ash cement materials. To this end, we evaluated the influence of the feed amount of limestone-fly ash mixture on the fine grinding.

\section{EXPERIMENTAL}

\subsection{Sample used}

The limestone used in this experiment was supplied by Ueda Lime Co., Ltd. The density and the Vickers hardness of the limestone were $2,680 \mathrm{~kg} \cdot \mathrm{m}^{-3}$ and $2.31 \mathrm{GPa}$, respectively. The limestone feed used in this study was prepared by crushing the raw material with a jaw crusher and classifying the crushed product with a $10^{3 / 20}$ or $10^{3 / 10}$ sieve.

The fly ash used was supplied by Sakata Kyodo Power Co., Ltd. The physical properties of the fly ash are listed in Table 1, and a scanning electron microscope (SEM) image of it is shown in Figure 1.

Table 1 Properties of the feed materials

\begin{tabular}{c} 
Limestone : Ueda Lime Co., Ltd. \\
Density \\
Vickers hardness $: 2,680 \mathrm{~kg} \cdot \mathrm{m}^{-3}$ \\
\hline
\end{tabular}

Fly ash : Sakata Kyodo Power Co., Ltd.

Density : $2,270 \mathrm{~kg} \cdot \mathrm{m}^{-3}$

Ash content $\quad .97 .0 \%$

Size range $: 1-150 \mu \mathrm{m}$

Median diameter : $15.6 \mu \mathrm{m}$

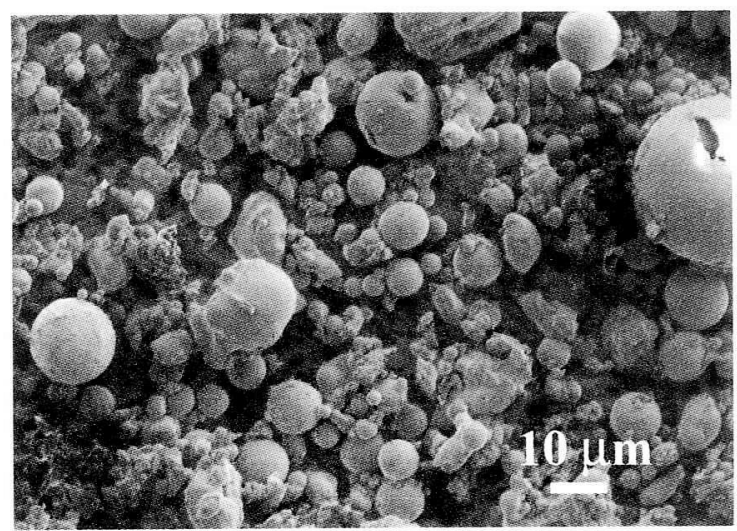

Figure 1 SEM micrograph of fly ash. 


\subsection{Experimental method}

2.2.1 Grinding apparatus: The grinding machine used in this study was a laboratory scale ball mill made of alumina with an inside diameter of $0.144 \mathrm{~m}$ and an inner volume of $2.1 \mathrm{dm}^{3}$. Alumina balls of $3,600 \mathrm{~kg} \cdot \mathrm{m}^{-3}$ in density and a ball diameter of $0.02 \mathrm{~m}$ were used as grinding media.

2.2.2 Grinding method: The feed size of limestone was 1,000 $850 \mu \mathrm{m}$. The ratio of the amount of limestone and fly ash in the feed was $5: 1$ [5], and the total feed amount was $0.20,0.24,0.28$ and $0.32 \mathrm{~kg}$. The balls, occupying about $50 \%$ of the mill volume, weighed $2.0 \mathrm{~kg}$. The rotational speed of the ball mill was set at $1.8 \mathrm{rps}$, which corresponds to $90 \%$ of the critical speed. Batch grinding tests were carried out for durations of $1 \sim 16 \mathrm{~h}$. Grinding conditions are tabulated in Table 2 . The grinding test of limestone alone, $0.20 \mathrm{~kg}$, which was the optimum grinding condition of limestone [5], also was performed.

2.2.3 Measurement of specific surface area of ground products : Samples of the ground products were degassed at $200^{\circ} \mathrm{C}$ for $1.5 \mathrm{~h}$, and their specific surface areas were measured by the BET adsorption method (Flowsorb 2300II, Shimadzu Corporation).

\subsubsection{Measurement of particle size distribution of ground} products: Ground products of the mixture were classified with testing sieves from $1,000 \mu \mathrm{m}$ to $75 \mu \mathrm{m}$ attached to a Ro-tap shaker. Particles finer than $75 \mu \mathrm{m}$ were measured by a laser diffraction and scattering method (Microtrac FRA, Nikkiso Co., Ltd.). The particle size distributions of limestone in the ground products were determined by the procedure as shown in Figure 2 because the main chemical components $\left(\mathrm{SiO}_{2}: 64-70 \%, \mathrm{Al}_{2} \mathrm{O}_{3}: 19-25 \%\right)$ of the residue obtained in Figure 2 were nearly equivalent to the components $\left(\mathrm{SiO}_{2}: 64 \%, \mathrm{Al}_{2} \mathrm{O}_{3}: 22 \%\right)$ of fly ash in this experiment.
Table 2 Grinding apparatus.

\begin{tabular}{c}
$\begin{array}{c}\text { Grinding machine : Ball mill } \\
\text { (Alumina) }\end{array}$ \\
Inside diameter : $0.144 \mathrm{~m}$ \\
Inner volume : $2.1 \mathrm{dm}^{3}$ \\
\hline Grinding media : Alumina ball \\
Density : $3,600 \mathrm{~kg} \cdot \mathrm{m}^{-3}$ \\
Ball diameter $: 0.02 \mathrm{~m}$
\end{tabular}

\section{RESULTS AND DISCUSSION}

\subsection{Ground products of limestone-fly ash mixture}

Figure 3 shows the relationship, for different feed amounts, between the specific surface area of the ground products $S_{\mathrm{w}}$ and the grinding time $t$. The specific surface area increases with increasing grinding time up to $12 \mathrm{~h}$ or $14 \mathrm{~h}$, and then decreases. This tendency was independent of the feed amount. The maximum value of the specific surface area depended on the feed amount and rose with additions to the feed amount.

Figures 4 and 5 show the cumulative undersize distributions of products ground for $4 \mathrm{~h}$ and $12 \mathrm{~h}$, respectively. In general, the size reduction was very effective in the initial stages of grinding, especially when the feed amount was $0.2 \mathrm{~kg}$. However, the most effective feed amount for the production of fine particles grew with increases in the grinding time.

Figure 6 shows the undersize distributions of the mixture under the limit of grinding for different feed amounts. A grinding time of $14 \mathrm{~h}$ was found to be useful for fine grinding, the mixture with a feed amount of $0.32 \mathrm{~kg}$.

Figure 7 shows the relationship between the median diameter of

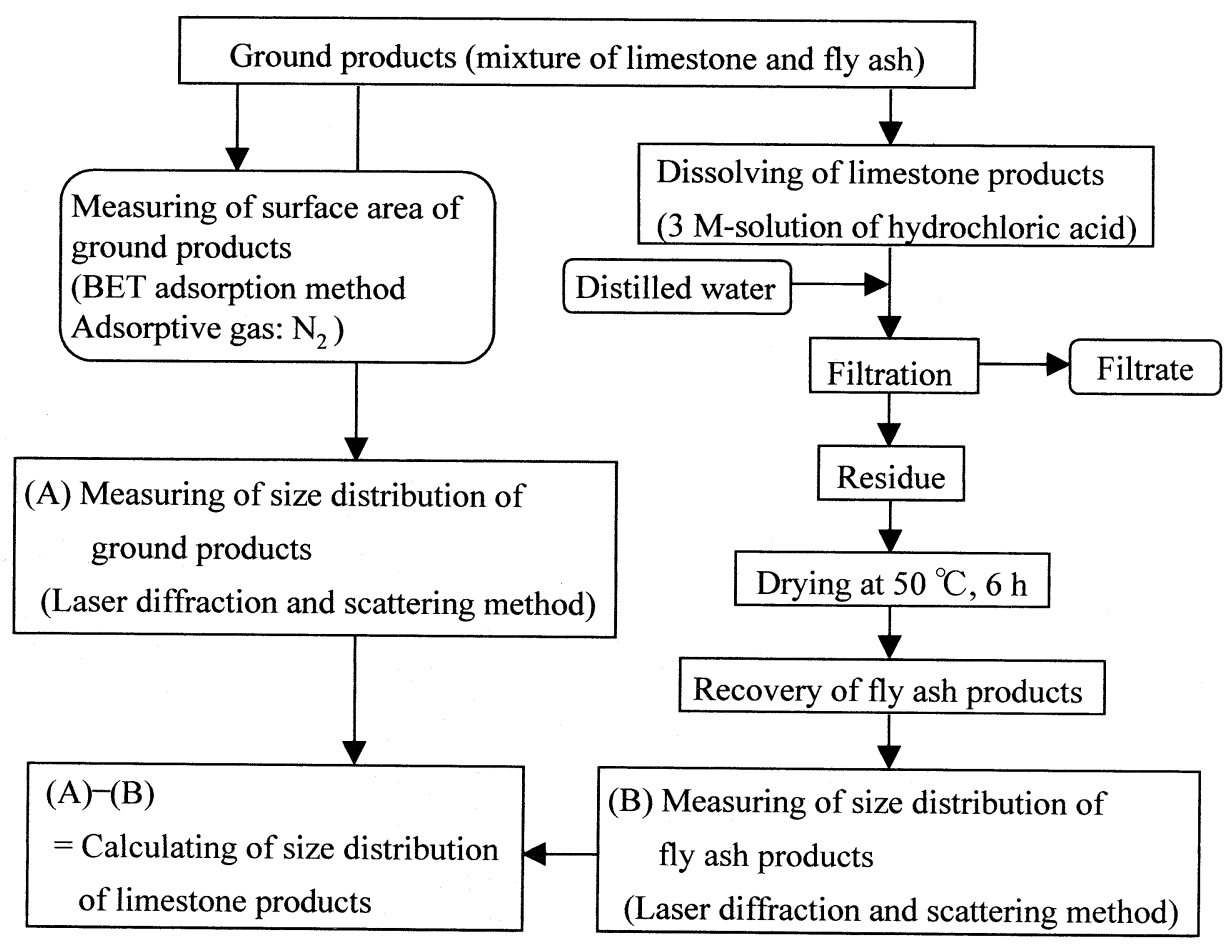

Figure 2 Processing scheme for the determination of the size distribution of limestone-fly ash mixture and limestone in ground products. 
the ground product, $x_{0.5}$, and the grinding time, $t$ for each feed amount. From these results, it was confirmed that the effect of the feed amount on the fine grinding was similar to the results shown in Figure 3.

Figure 8 shows the relationship between the median diameter, $x_{0.5}$, and the specific surface diameter, $x_{S_{\mathrm{w}}}$, of the ground products. The correlation found between the two diameters can be expressed as follows :

$$
x_{0.5}=4.09 x_{S_{\mathrm{w}}}{ }^{1.81} \quad\left(x_{S_{\mathrm{w}}}=\frac{6}{\rho S_{\mathrm{w}}}\right)
$$

where $\rho$ is the density of the mixture of limestone and fly ash. From this empirical equation, it is possible to use the specific surface area to evaluate the median diameter, regardless of the feed amount and grinding time.

\subsection{Ground products of limestone in limestone-fly ash mixture}

Figures 9 and 10 show the size distributions of the limestone products in mixtures ground for $4 \mathrm{~h}$ and $12 \mathrm{~h}$, respectively, together with the size distributions of the ground products for limestone alone. These results indicated that the addition of fly ash is effective for a satisfactory limestone grinding.

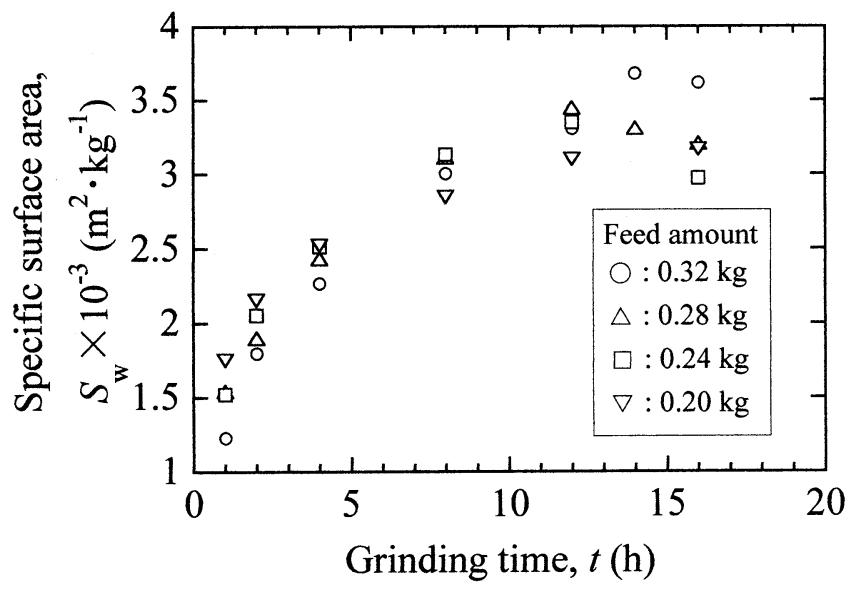

Figure 3 Relationship between specific surface area, $S_{\mathrm{w}}$ and grinding time $t$ for ground products of mixture.

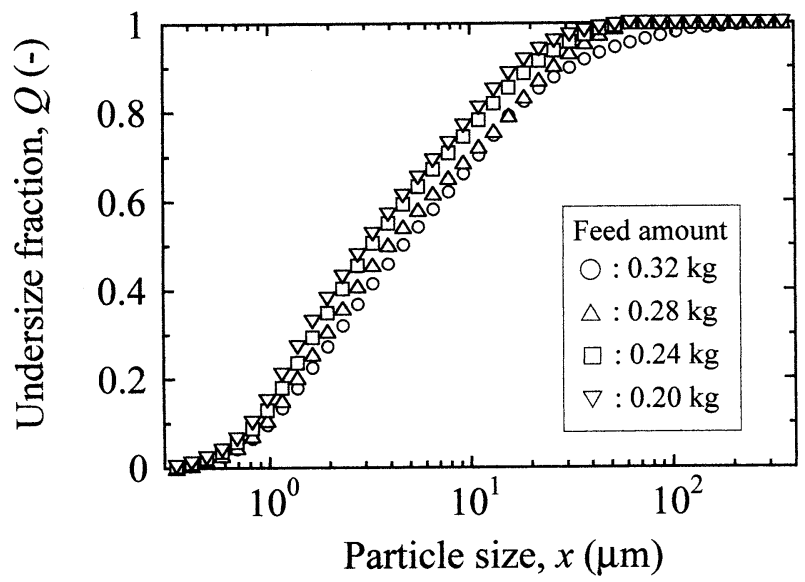

Figure 4 Size distributions of limestone-fly ash mixture ground for 4 hours.
Figure 11 shows the size distributions, for different feed amounts, of limestone ground to the grinding limit. Fine grinding of the limestone was achieved when the feed amount of the

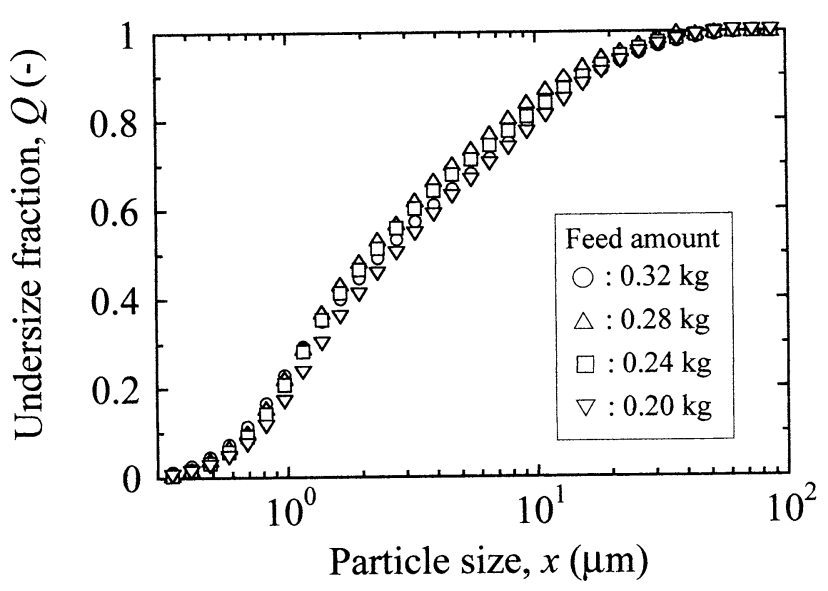

Figure 5 Size distributions of limestone-fly ash mixture ground for 12 hours.

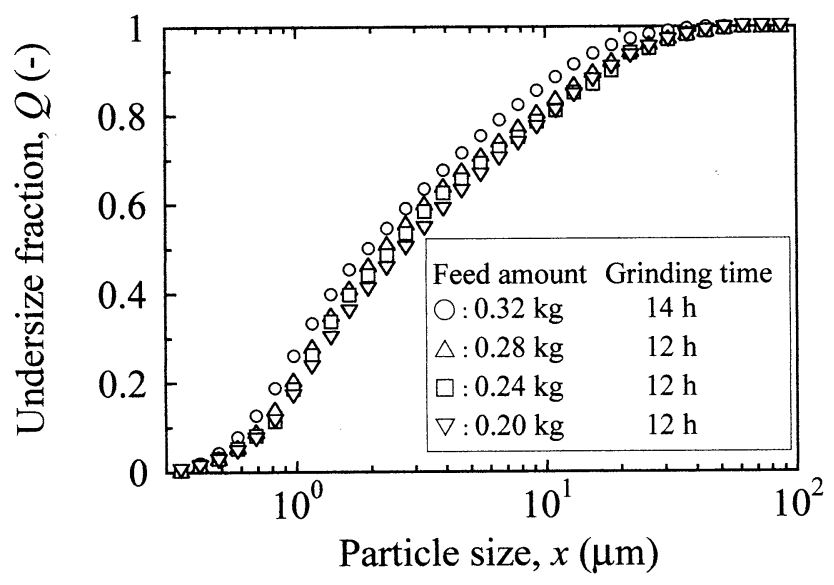

Figure 6 Size distributions of the limestone-fly ash mixture with different feed amounts and ground to the limit.

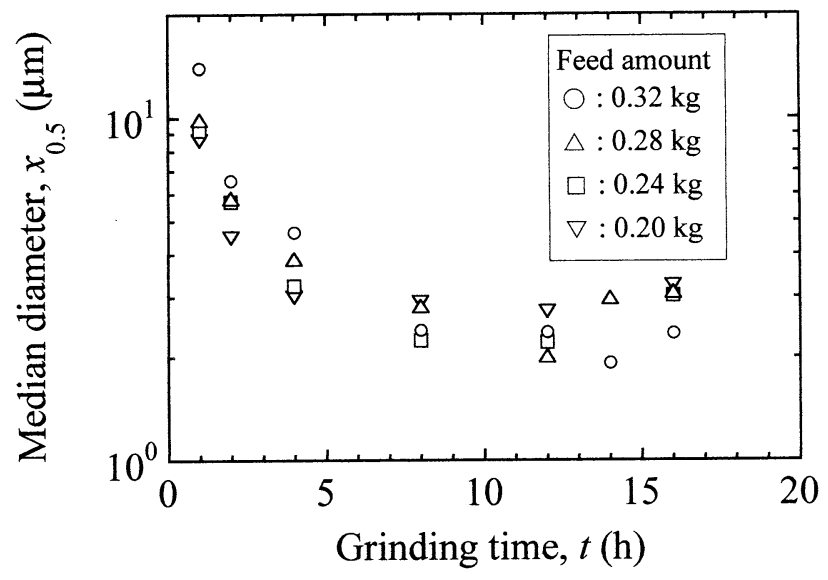

Figure 7 Relationship between median diameter, $x_{0.5}$ and grinding time, $t$ for the ground products of the mixture. 


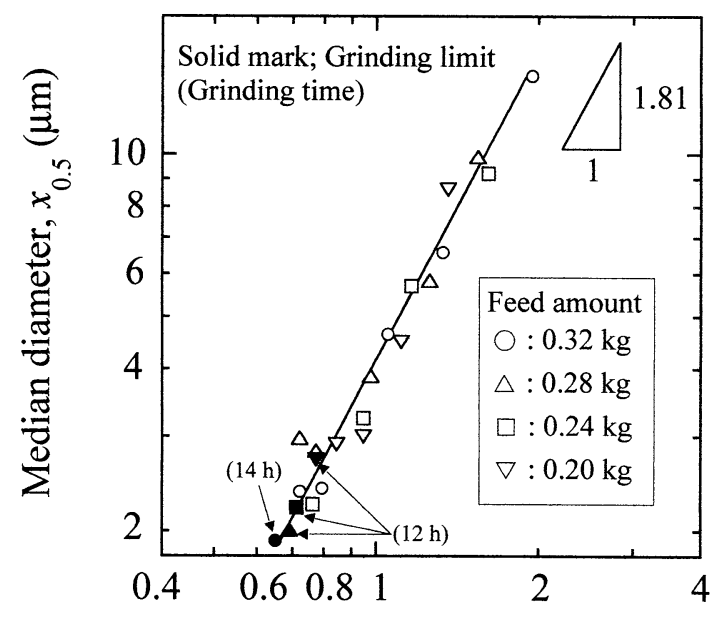

Specific surface diameter, $x_{S \mathrm{~W}}(\mu \mathrm{m})$

Figure 8 Relationship between median diameter, $x_{0.5}$ and specific surface diameter, $x_{S_{\mathrm{W}}}$ for the ground products of mixture.

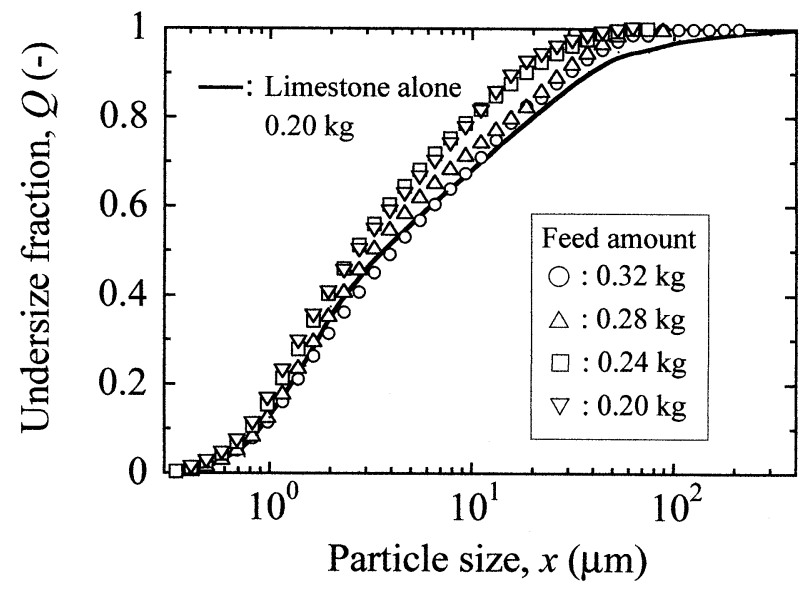

Figure 9 Size distributions of limestone ground for 4 hours.

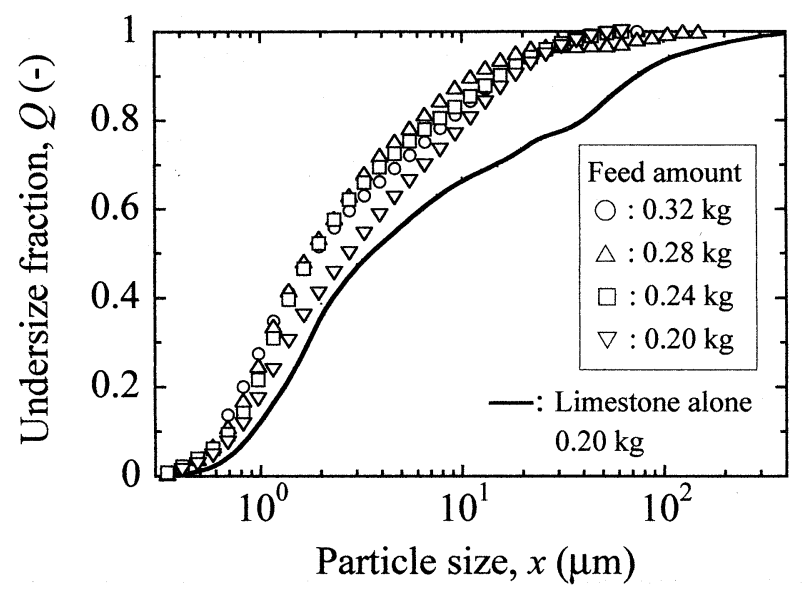

Figure 10 Size distributions of limestone ground for 12 hours.

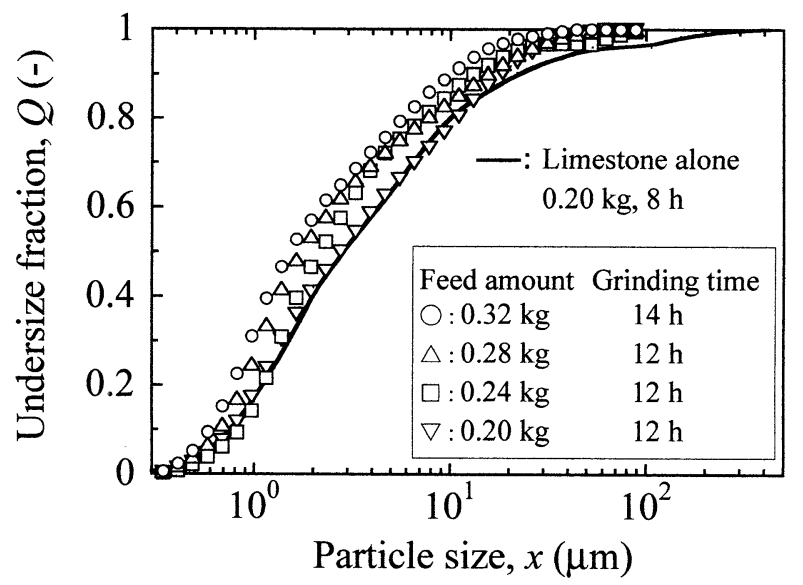

Figure 11 Size distributions of limestone with different amounts and ground to the limit.

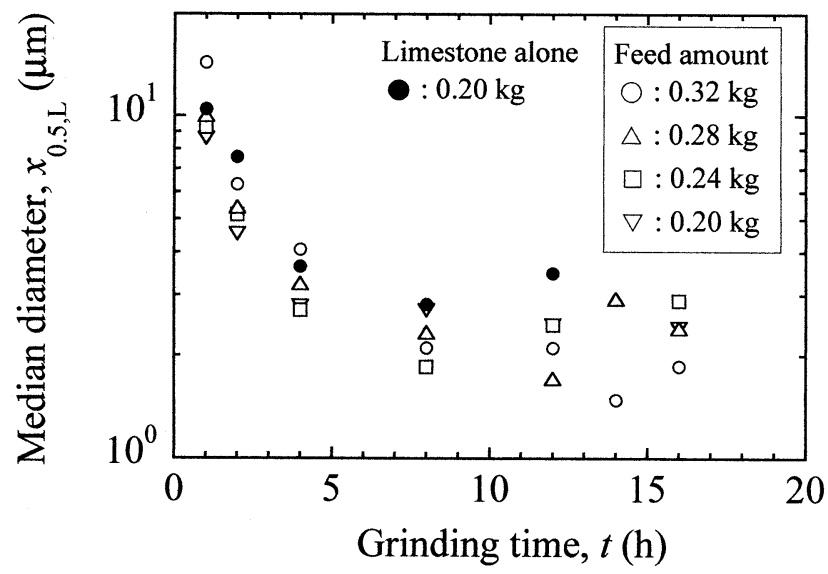

Figure 12 Relationship between median diameter, $x_{0.5, \mathrm{~L}}$ and grinding time, $t$ for the ground products of limestone.

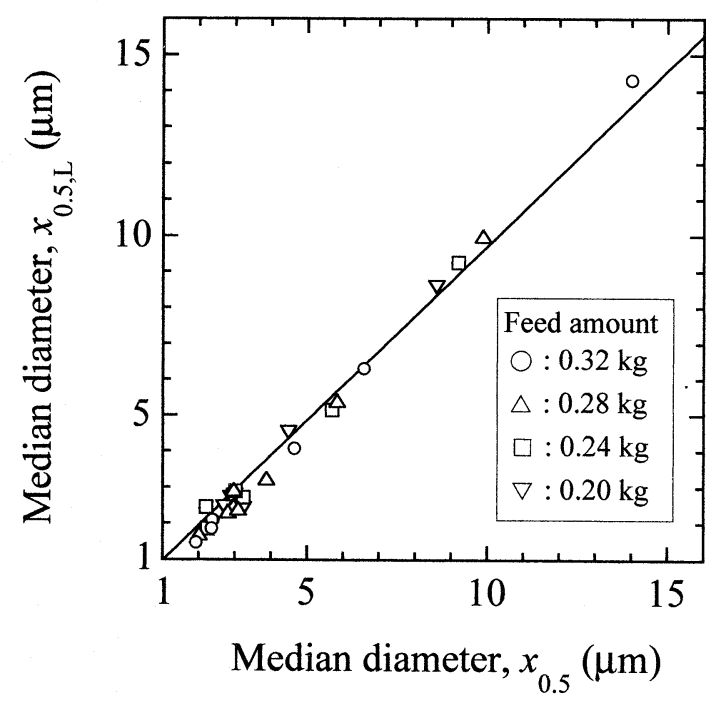

Figure 13 Relationship between median diameter of limestone, $x_{0.5 \mathrm{~L}, \mathrm{~L}}$ and limestone-fly ash mixture, $x_{0.5}$. 
mixture was $0.32 \mathrm{~kg}$ and the grinding time, $14 \mathrm{~h}$.

Figure 12 shows the relationship, for the same feed amounts, between the median diameter of the limestone products, $x_{0.5, \mathrm{~L}}$, and the grinding time, $t$. From the results shown in these two figures, it was concluded that the limestone grindings with higher feed amounts require longer time duration.

Figure 13 indicates the relationship between the median diameters of the limestone, $x_{0.5, \mathrm{~L}}$, and the limestone-fly ash mixture, $x_{0.5}$, for different feed amounts. The median diameter of the limestone alone was about $3 \%$ less than that of the mixture. The equation below describes the relationship:

$$
x_{0.5, \mathrm{~L}}=0.97 x_{0.5}
$$

Evidently, the ground products of the mixture consist mostly of limestone particles. The fine grinding was less effective in breaking the fly ash particles, and, for the most part, occurred through the size reduction of the limestone particles. This result may be explained by an adhesion of the fly ash, made up of spherical particles as shown in Figure 1, to the limestone surface. This adhesion evidently improved the flowability of the limestone particles, so that the collision frequency of the balls and particles increased, and the breakage in the ball mill became more effective.

\section{CONCLUSION}

Fly ash, generated mainly at coal-fired electric power plants, is utilized as part of a cement mixture or as cement raw material, while limestone is the main raw material of cement.

In this study, we performed batch ball mill grindings of limestone with fly ash as a grinding aid, and investigated the influences of the feed amount on the grindability of the mixture or limestone. The results are summarized as follows:

(1) Within the experimental limits, increases in the feed amount of limestone and fly ash mixture enhanced the fine grinding of the mixture or limestone.

(2) For the ground products of the mixture, we noted a correlation between the median particle diameter, determined by laser diffraction and scattering, and the surface area diameter, evaluated by the BET method. This relationship was independent of the feed amount and grinding time.
(3) Fly ash was found to be an effective grinding aid for the fine grinding of the limestone cement material.

\section{Acknowledgments}

The authors would like to thanks Ueda Lime Co., Ltd. and Sakata Kyodo Power Co., Ltd. for supplying the test samples.

\section{Nomenclature}

$S_{\mathrm{w}}$ : specific surface area of ground products of the mixture

$t:$ grinding time $\left(\mathrm{m}^{2} \cdot \mathrm{kg}^{-1}\right)$

$Q:$ undersize fraction

$x$ : particle size

$x_{0.5}:$ median diameter of ground products of the mixture $(\mu \mathrm{m})$

$x_{0.5, \mathrm{~L}}:$ median diameter of ground products of limestone in the mixture

$(\mu \mathrm{m})$, (m)

$x_{S_{\mathrm{w}}}$ : specific surface diameter of ground products of the mixture $(\mu \mathrm{m}),(\mathrm{m})$

$\rho:$ density of the mixture of limestone and fly ash $\left(=2,600 \mathrm{~kg} \cdot \mathrm{m}^{-3}\right)$

$\left(\mathrm{kg} \cdot \mathrm{m}^{-3}\right)$

\section{References}

[1] The Center for Coal Utilization, Japan : National Coal Ash Fact-Finding Survey Report (2001 results), (2003).

[2] El-Shall, S. and Somasundaran, P., " Physico-Chemical Aspects of Grinding : a Review of Use of Additives”, Powder Technology, Vol.38, pp.275-293 (1984).

[3] Sohoni, S., Sridhar, R. and Mandal, G., "The Effect of Grinding Aids on the Fine Grinding of Limestone, Quartz and Portland Cement Clinker", Powder Technology, Vol.67, pp.277-286 (1991).

[4] Moothedath, S. K., and Ahluwalia, S. C., " Mechanism of Action of Grinding Aids in Comminution" , Powder Technology, Vol.71, pp.229-237 (1992).

[5] Kotake, N., Hanashima, H., Okazaki, K. and Kanda, Y., "Study on Use of Fly Ash -Fine Grinding of Limestone Using Fly Ash as a Grinding Aid-" , Preprints of $3^{\text {rd }}$ Symposium of Powder and Recycling, Miyagi, Japan, pp.3740, 2004. 